\title{
Synoptic-scale controls of persistent low temperature and icy weather over southern China in January 2008
}

Article

Published Version

Zhou, W., Chan, J. C. L., Chen, W., Ling, J., Pinto, J. G. and Shao, Y. (2009) Synoptic-scale controls of persistent low temperature and icy weather over southern China in January 2008. Monthly Weather Review, 137 (11). pp. 3978-3991. ISSN 0027-0644 doi: https://doi.org/10.1175/2009MWR2952.1 Available at https://centaur.reading.ac.uk/32777/

It is advisable to refer to the publisher's version if you intend to cite from the work. See Guidance on citing.

Published version at: http://dx.doi.org/10.1175/2009MWR2952.1

To link to this article DOI: http://dx.doi.org/10.1175/2009MWR2952.1

Publisher: American Meteorological Society

All outputs in CentAUR are protected by Intellectual Property Rights law, including copyright law. Copyright and IPR is retained by the creators or other copyright holders. Terms and conditions for use of this material are defined in the End User Agreement.

www.reading.ac.uk/centaur 
Central Archive at the University of Reading

Reading's research outputs online 


\title{
Synoptic-Scale Controls of Persistent Low Temperature and Icy Weather over Southern China in January 2008
}

\author{
WEN ZHOU AND JOHNNY C. L. CHAN \\ Guy Carpenter Asia-Pacific Climate Impact Centre, City University of Hong Kong, Hong Kong, China \\ WEN CHEN AND JIAN LING \\ Institute of Atmospheric Physics, Chinese Academy of Sciences, Beijing, China \\ JOAQUIM G. PINTO AND YAPING SHAO \\ Institute for Geophysics and Meteorology, University of Cologne, Cologne, Germany
}

(Manuscript received 20 January 2009, in final form 21 May 2009)

\begin{abstract}
In January 2008, central and southern China experienced persistent low temperatures, freezing rain, and snow. The large-scale conditions associated with the occurrence and development of these snowstorms are examined in order to identify the key synoptic controls leading to this event. Three main factors are identified: 1) the persistent blocking high over Siberia, which remained quasi-stationary around $65^{\circ} \mathrm{E}$ for 3 weeks, led to advection of dry and cold Siberian air down to central and southern China;2) a strong persistent southwesterly flow associated with the western Pacific subtropical high led to enhanced moisture advection from the Bay of Bengal into central and southern China; and 3) the deep inversion layer in the lower troposphere associated with the extended snow cover over most of central and southern China. The combination of these three factors is likely responsible for the unusual severity of the event, and hence a long return period.
\end{abstract}

\section{Introduction}

The winter climate in East Asia is dominated by the Siberian high over the Eurasia continent and the Aleutian low over the North Pacific at mid- and high latitudes. In the boreal winter, Southeast Asia is frequently affected by the East Asia winter monsoon, the most prominent surface feature of which are cold outbreaks induced by strong northwesterly winds along the eastern flank of the Siberian high, leading in turn to rapid temperature drops in southern China (Ding 1994; Wu and Chan 1995, 1997; Chang 2004, chapter 2). Severe cold spells are brought by this northwesterly flow to southern China. Note that the large-scale sinking motion to the back of the East Asian trough together with the strong radiative cooling contributes to a rapid build up of the Siberian high and cold surges sweeping across East

Corresponding author address: Wen Zhou, Guy Carpenter AsiaPacific Climate Impact Centre, City University of Hong Kong, Tat Chee Ave 83, Kowloon, Hong Kong, China.

E-mail:wenzhou@cityu.edu.hk
Asia and penetrating into southern China (Ding and Krishnamurti 1987; Wu and Chan 1997).

In January and early February 2008, an anomalously strong East Asian winter monsoon occurred with extremely low temperatures, blizzard conditions, and freezing rain in southern China. This extreme event caused extensive damage and general disruption over southern China. Most of the infrastructure damages were attributed to freezing rain, which led to a huge number of broken power transmission lines and chaotic traffic conditions for southern China. The disastrous heavy snow caused serious direct economic losses of 53.8 billion RMB. All these facts motivate an analysis of the synoptic-scale systems/patterns associated with this extreme occurrence. In particular, the following questions are important: What is the return period of this extreme event? What caused this extreme cold weather in South China? How strong is the East Asian winter monsoon? What forcing mechanisms may have played a role in the event?

The datasets are first described in section 2. Some details about the extensive area of persistent low 


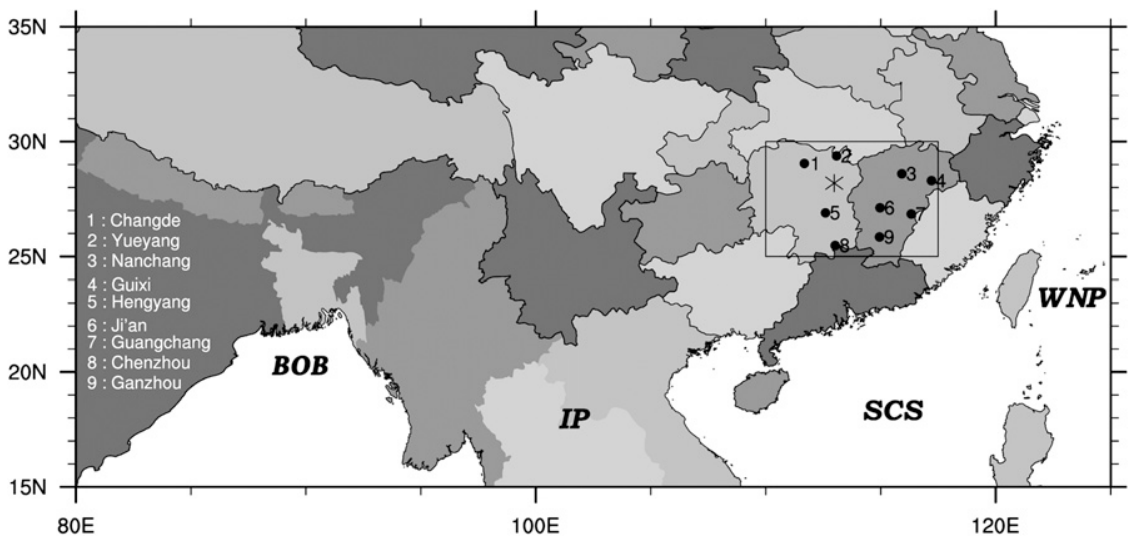

FIG. 1. Area in southern China most severely hit by the snowstorm events [box indicates Hunan (west) and Jiangxi (east) provinces; asterisk indicates Changsha station; BOB, IP, SCS, and WNP refer to the Bay of Bengal, Indochina Peninsula, South China Sea, and western North Pacific, respectively]. The numbers correspond to the location of the selected stations (1: Changde, 2: Yueyang, 3: Nanchang, 4: Guixi, 5: Hengyang, 6: Ji'an, 7: Guangchang, 8: Chenzhou, and 9: Ganzhou).

temperatures and rain, snow, and ice in southern China in January-February 2008 are given in section 3. How the observed extreme values compared with the historic context of instrumental observations is also discussed. Analyses of the synoptic-scale systems and large-scale patterns are presented in section 4 to explain the possible causes of the unusual event. A short discussion in section 5 concludes this paper.

\section{Data and methodology}

\section{a. Data}

The data used in this study are mainly from the National Centers for Environmental Prediction-National Center for Atmospheric Research (NCAR-NCEP) reanalysis (Kalnay et al.1996). These include the daily mean and long-term mean values of air temperature, geopotential height, wind speed, surface temperature, and surface pressure. The horizontal resolution of these data is $2.5^{\circ}$ latitude $\times 2.5^{\circ}$ longitude. The SST data are from the National Oceanic and Atmospheric Administration (NOAA) Extended Reconstructed SST dataset with a horizontal resolution of $2.0^{\circ}$ latitude $\times 2.0^{\circ}$ longitude.

Snow-cover data derived from NOAA visible satellite charts $(89 \times 89$ Northern Hemisphere grid $)$ are from Rutgers University Climate Laboratory (RUCL; Robinson et al. 1993). Monthly, weekly, and daily series of snow extent for Eurasia (available online at http:// climate.rutgers.edu/snowcover/index.php) are also considered. The index for the Scandinavia pattern (Eurasia-1 pattern; Barnston and Livezey 1987), obtained from the first rotated empirical orthogonal function (EOF) of 700-hPa fields, is obtained from the Climatic Prediction Center (available online at http://www.cpc.noaa.gov).
Daily surface temperature and snow water equivalent (SWE) data of 593 China meteorological stations compiled by the China Meteorological Administration are also used. The time period studied is from 1 January to 2 February 2008. For studying the extreme synoptic weather event over South China in detail, we will focus on nine observation stations that represent the region most severely hit by the disastrous snowstorms (Fig. 1).

\section{b. Methodology}

To estimate the return period of the occurrence of the persistent low temperature, the Gumbel distribution (Gumbel 1960,1961) is used to estimate the return period of the average temperature during the second 10 days (11-20) and the third 10 days (21-30) of January 2008. Its probability density function is

$F(x)=\left(\frac{1}{\beta}\right) \exp \left\{-\exp \left[\frac{-(x-\alpha)}{\beta}\right]-\frac{(x-\alpha)}{\beta}\right\}$,

TABLE 1 . The location $\alpha_{1}\left(\alpha_{2}\right)$ and scale $\beta_{1}\left(\beta_{2}\right)$ parameters for 9 observational stations in southern China during the second (third) 10 days of January 2008 (units: ${ }^{\circ} \mathrm{C}$ ). The climatological reference period is $1955-2007$.

\begin{tabular}{lcccc}
\hline \multicolumn{1}{c}{ Station } & $\alpha_{1}$ & $\beta_{1}$ & $\alpha_{2}$ & $\beta_{2}$ \\
\hline 1 (57662 Changde) & 5.467 & -0.631 & 5.601 & -0.538 \\
2 (57584 Yueyang) & 5.421 & -0.585 & 5.794 & -0.499 \\
3 (58606 Nanchang) & 5.817 & -0.628 & 6.308 & -0.527 \\
4 (58626 Guxi) & 6.742 & -0.586 & 7.365 & -0.535 \\
5 (57872 Hengyang) & 6.675 & -0.539 & 6.865 & -0.487 \\
6 (57799 Ji'an) & 7.064 & -0.595 & 7.578 & -0.491 \\
7 (58813 Guangchang) & 7.249 & -0.550 & 7.863 & -0.480 \\
8 (57972 Chenzhou) & 6.979 & -0.494 & 7.423 & -0.453 \\
9 (57993 Ganzhou) & 8.926 & -0.524 & 9.422 & -0.446
\end{tabular}



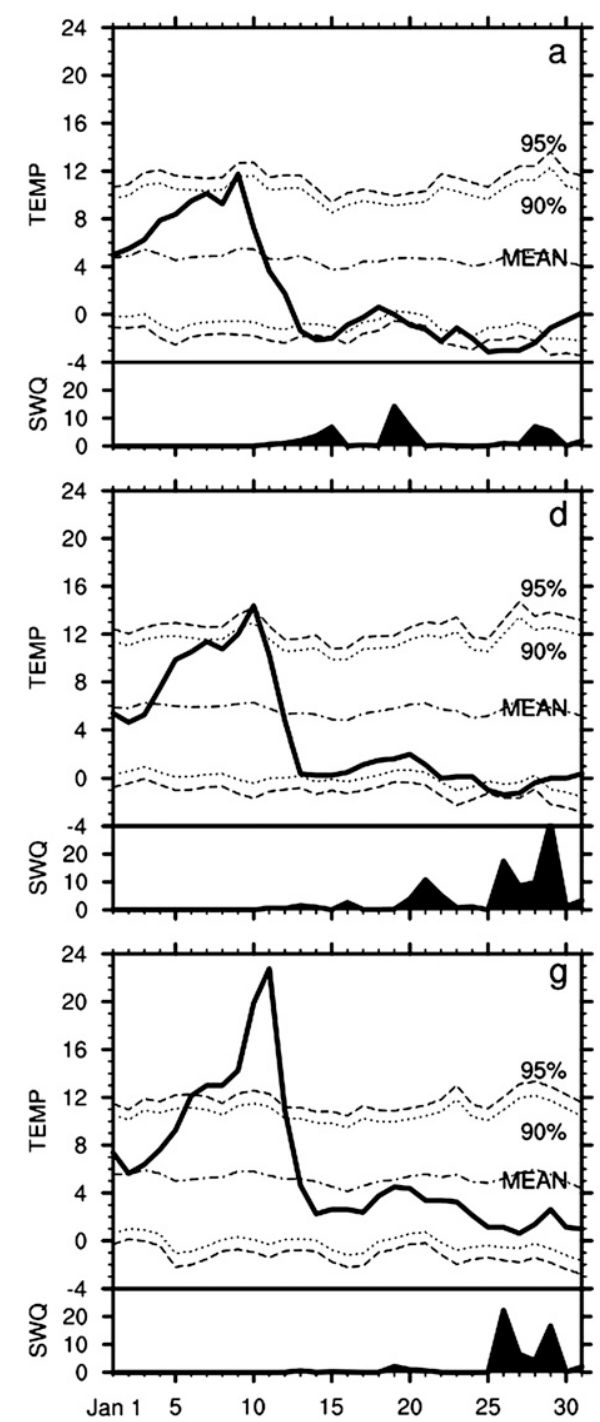
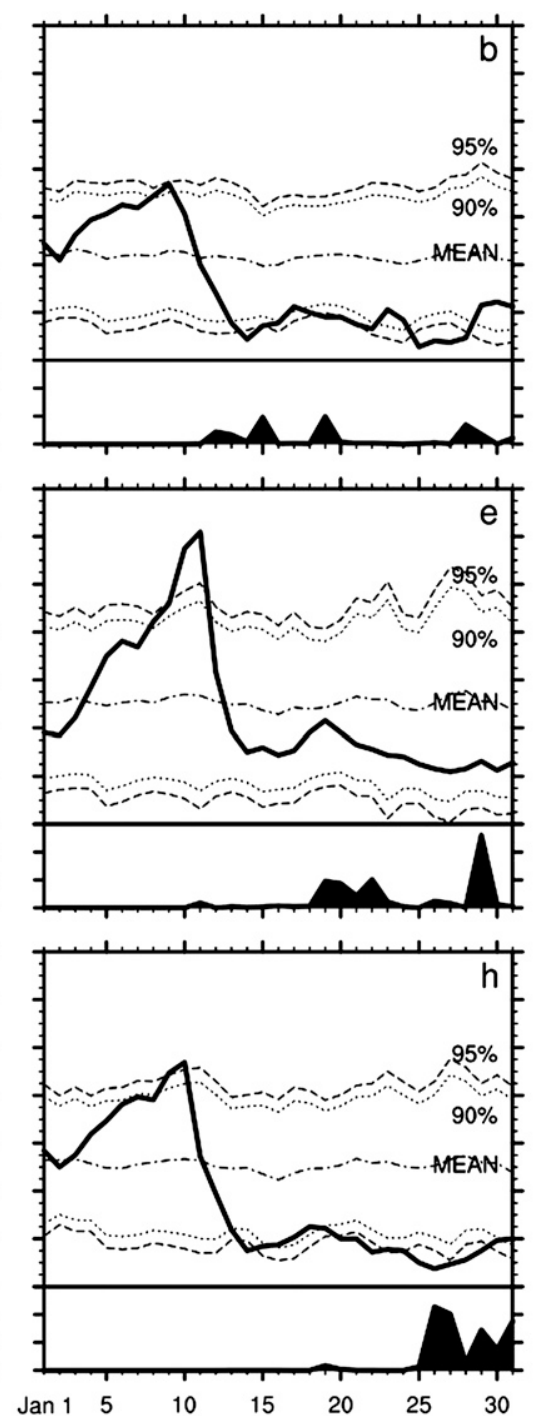
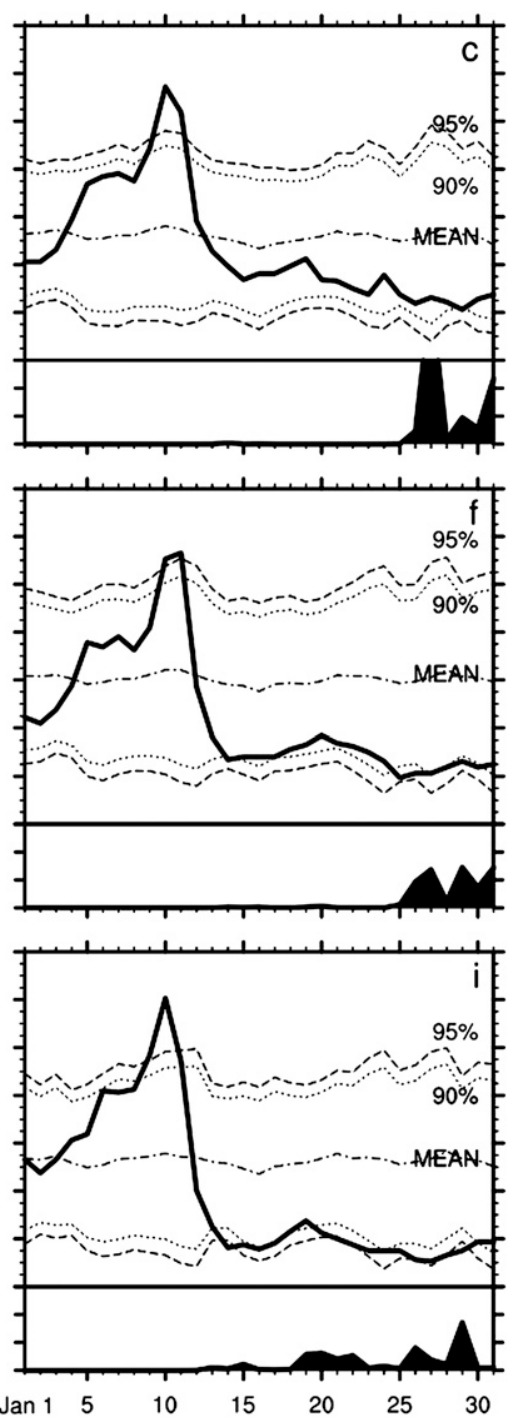

FIG. 2. Temperature variations of daily mean temperature (solid line, ${ }^{\circ} \mathrm{C}$ ) and SWE (shaded area, mm) in southern China at nine observation stations: (a) Changde, (b) Yueyang, (c) Nanchang, (d) Guixi, (e) Hengyang, (f) Ji'an, (g) Guangchang, (h) Chenzhou, and (i) Ganzhou for January 2008. Dot-dashed line represents the long-term average mean daily temperature $\left(1955-2007,{ }^{\circ} \mathrm{C}\right)$ and the dotted (dashed) lines the 95th (99th) percentile value $\left({ }^{\circ} \mathrm{C}\right)$.

where $\alpha$ and $\beta$ are the location and scale parameters, respectively.

The parameter estimation in the probability density function is calculated using the maximum likelihood approach (more detail in Chen and Huang 1995). The values of $\alpha$ and $\beta$ for the nine southern China stations during the second and third 10 days of January 2008 are shown in Table 1.

\section{Description of the extreme snowstorm event in January-February 2008}

The 2008 Chinese winter was associated with a series of snowstorms and extremely low temperatures affecting southern China. Starting 10 January 2008, four significant snowstorm events (10-15 January, 18-22 January, 25-28 January, and 31 January-2 February) occurred in China south of the Yangtze River. The daily snow cover data from RCUL shows that the snow cover over China increases significantly starting on 12 January, and eventually covered most of the country (including our investigated area) by the end of January (cf. RCUL's Web site). Moreover, many cities in southern China were affected by freezing rain and icy weather. This disastrous weather episode was extraordinary not only in terms of intensity but also in terms of extent, as it affected a very large area.

The temperature of the nine stations most severely hit by the snowstorms are either close to or above average 
during the first 10 days of January 2008 (Fig. 2), in fact even exceeding the 95 th percentile values of the period 1955-2007 for a few stations (Guixi in Fig. 2d; Guangchang in Fig. 2g; and Ganzhou in Fig. 2i). With the beginning of the first event on 10 January, the temperature dropped very sharply at all 9 stations (particularly around 12-13 January) and subsequently remaind below average (and for most stations close to the 90th or 95th percentiles values for the period 1955-2007) until early of February. The average temperatures of the second 10 days of January (11-20 January) 2008 for the 9 stations vary from $-0.2^{\circ}$ to $6.1^{\circ} \mathrm{C}$, which is $0.4^{\circ}-4.7^{\circ} \mathrm{C}$ below the climatological mean (Table 2). In the remainder of the month (21-30 January), the average temperature of South China is $4.8^{\circ}-7.1^{\circ} \mathrm{C}$ below normal, with nine sites having record low average temperatures.

Snow (quantified as SWE in millimeters) also occurred in some of the stations (Fig. 2), but instead of melting after each event it accumulated as the temperatures remained quasi-constant near $0^{\circ} \mathrm{C}$ until early February. The snow accumulated even though the SWE over these nine sites is in fact not very large. After 30 January 2008, the temperatures slowly rose to average values by mid-February (not shown).

Using the Gumbel distribution, the return periods of the average temperature of the second and third 10 days in January 2008 for the 9 southern China stations (significant at $95 \%$ confidence level) can be estimated (see the appendix). The temperatures of the second 10 days in January 2008 observed in Hunan province correspond to a return period of $10-30 \mathrm{yr}$ (e.g., 25-30 yr for Yueyang and Changde and 10-20 yr for Hengyang and Chenzhou). But the temperatures of the third 10 days in January 2008 observed in all 9 stations have a return period of 23-56 yr. In particular, the temperatures observed in Yueyang, Hengyang, and Chenzhou show a return period of 44,56 , and $43 \mathrm{yr}$, respectively.

\section{Large-scale conditions during the event in January-February 2008}

\section{a. Blocking pattern}

Starting on 10 January 2008, the temperature over central and southern China decreased substantially because of cold-air intrusions from the north, originating from the Lake Baikal region (centerpoint: $54^{\circ} \mathrm{N}, 109^{\circ} \mathrm{E}$ ) and extending down to central and southern China $\left(30^{\circ}-25^{\circ} \mathrm{N}, 110^{\circ}-120^{\circ} \mathrm{E}\right)$. During the second and the third 10 days in January 2008, a blocking high formed over the Ural-Siberia region (Figs. 3a,b). Colder air over the polar region and a stronger Siberian high are found
TABLE 2. Mean temperature $\left(\langle T\rangle,{ }^{\circ} \mathrm{C}\right)$, deviation from the climatological average $\left(\mathrm{Dev},{ }^{\circ} \mathrm{C}\right)$, and estimated return period (RT, yr) for the second and third 10 days of January 2008. The climatological reference period is 1955-2007.

\begin{tabular}{crrrrrrr}
\hline \hline & \multicolumn{3}{c}{ 11-20 Jan } & & \multicolumn{3}{c}{ 21-30 Jan } \\
\cline { 2 - 4 } \cline { 6 - 8 } Station & $\langle T\rangle$ & Dev & RT & & $\langle T\rangle$ & Dev & RT \\
\hline 1 & 0.0 & -4.6 & 31 & & -1.0 & -5.6 & 35 \\
2 & -0.2 & -4.7 & 27 & & -1.8 & -6.5 & 44 \\
3 & 2.3 & -2.6 & 9 & -0.2 & -5.5 & 31 \\
4 & 5.4 & -0.4 & 2 & & 1.5 & -4.8 & 23 \\
5 & 1.1 & -4.6 & 20 & -1.4 & -7.1 & 56 \\
6 & 4.4 & -1.7 & 5 & & 1.2 & -5.3 & 23 \\
7 & 5.3 & -0.9 & 3 & & 1.3 & -5.4 & 23 \\
8 & 2.0 & -3.9 & 11 & -0.9 & -7.1 & 43 \\
9 & 6.1 & -1.8 & 4 & 2.0 & -6.2 & 27 \\
\hline
\end{tabular}

during the extreme snowstorm period in January 2008 (Figs. 3a,b). This blocking high also had an extraordinary persistence, as the blocking frequencies (derived after Tibaldi and Molteni 1990) in January 2008 for the longitudes $40^{\circ}-80^{\circ} \mathrm{E}$ exceed the climatological (19552007) 95th percentile (Fig. 4). In particular, the blocking frequencies in the longitude band $57.5^{\circ}-67.5^{\circ} \mathrm{E}$ are the highest on record, indicating the extraordinary characteristics of this event. Note that elsewhere over the Northern Hemisphere midlatitudes, the month of January 2008 was characterized by a generally zonal flow and hence below-average blocking frequencies, particularly over the North Atlantic and North Pacific basins (cf. Fig. 3).

The evolution process of the first snowstorm event during 10-15 January is illustrated in Fig. 5. The positive value of the 24-h surface pressure difference in Fig. 5 shows a sharp rise of pressure, together with the strengthening of the northwesterly and the extremely tight meridional temperature gradient in southern China, which indicates that the cold monsoonal flow moved eastward off the continent and penetrated into southern China. Compared to its climatological value along the Yangtze River basin, the $0^{\circ}$ isotherm shown in Fig. 5 was displaced more than $1000 \mathrm{~km}$ southward during the 5-day period of 10-15 January.

This was the first and the strongest cold wave that hit southern China during the prolonged episode. In the next three cold surges, the cold events (18-22 January, 25-28 January, and 31 January-2 February) were not as strong because the 24-h surface pressure difference and the northerly wind at $850 \mathrm{hPa}$ were weaker (Figs. 6-8). From 18 January-2 February, the surface temperature over central and South China was below $0^{\circ} \mathrm{C}$, and more water vapor was transported (Figs. 9-10) to southern China by the strong southwesterlies; the pressure tendency (24-h SLP difference) indicates that the cold air 
(a)

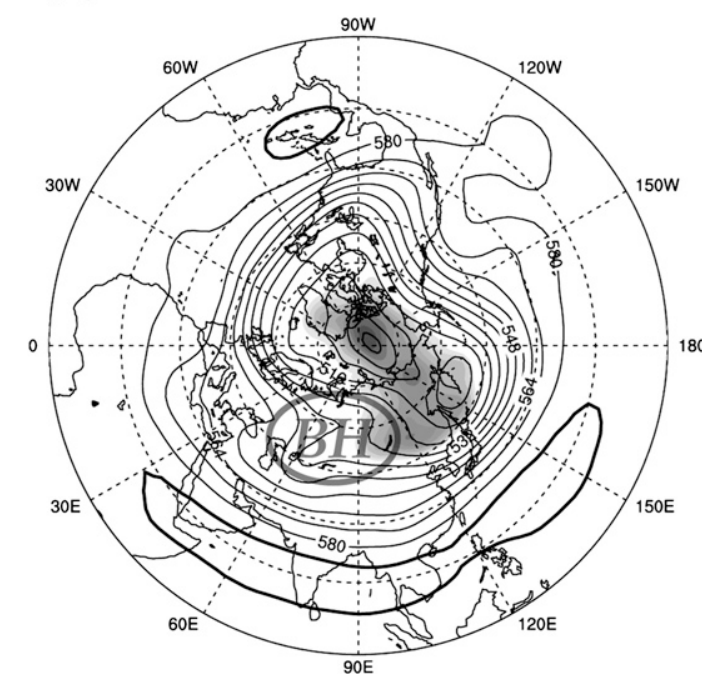

(b)

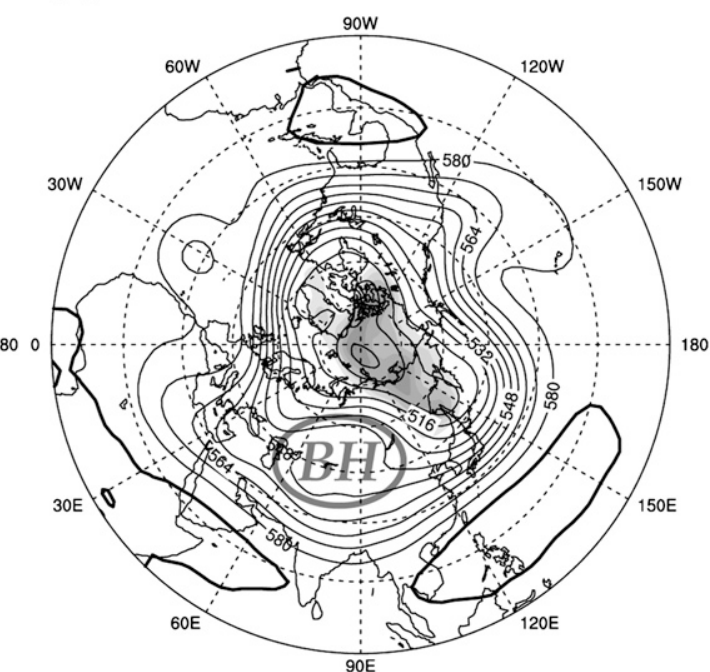

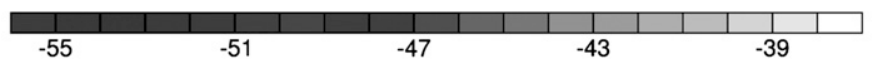

FIG. 3. Geopotential height (contour, gpm) and air temperature (shaded, ${ }^{\circ} \mathrm{C}$ ) at $500 \mathrm{hPa}(\mathrm{a})$ the second 10 days of January 2008 and (b) the third 10 days of January 2008. The thick solid line in (b) is the 5860-gpm contour and BH indicates the Ural blocking high.

moved more eastward than southward. Though the cold air from the north shown in Figs. 6-8 was not as strong as the first event in Fig. 5, the increased water vapor brought to central and southern China (Figs. 9-10) with a cold ground temperature was the reason for the freezing rain. Note that the $0^{\circ} \mathrm{C}$ isotherm over southern China was quasi-stationary during these four snow events, suggesting that the heavy snow cover supported the persistence of widespread low surface temperatures over southern China.

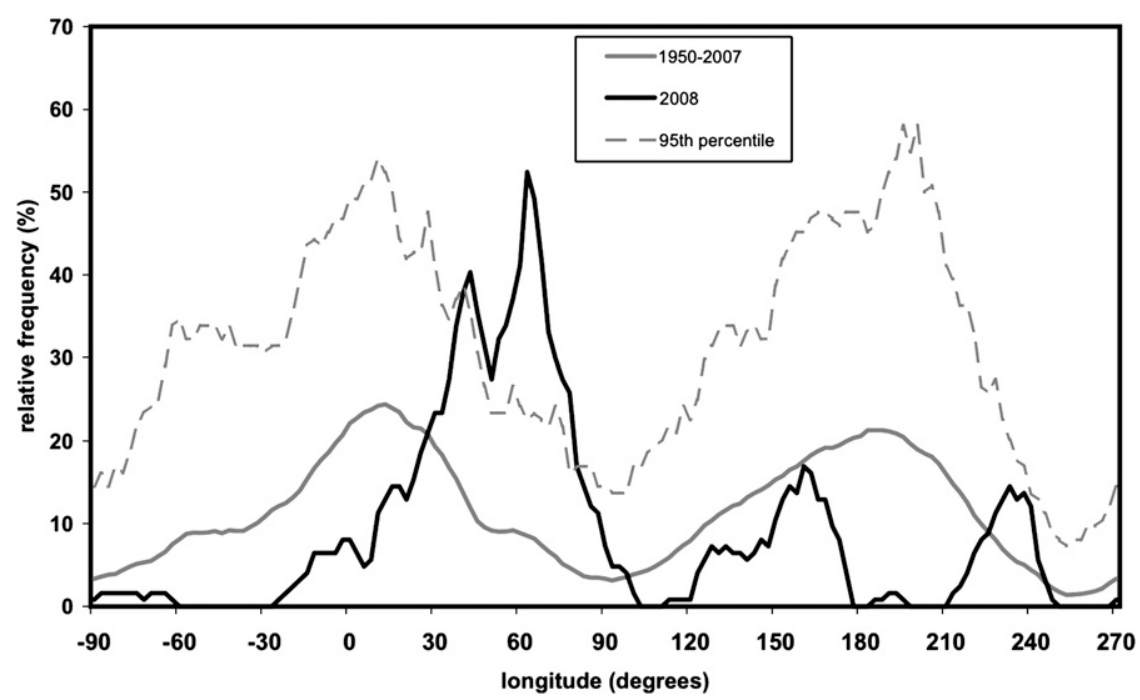

FIG. 4. Blocking index for the Northern Hemisphere midlatitudes for the January 2008. Values are computed on a daily basis and are given as relative frequencies vs longitude: percentage of block days per month ( $y$ axis) and longitude ( $x$ axis). Values for January 2008 (red line), NCEP mean value for January 1950-2007 (black line), and 95th percentile value for 19502007 (dashed line). 

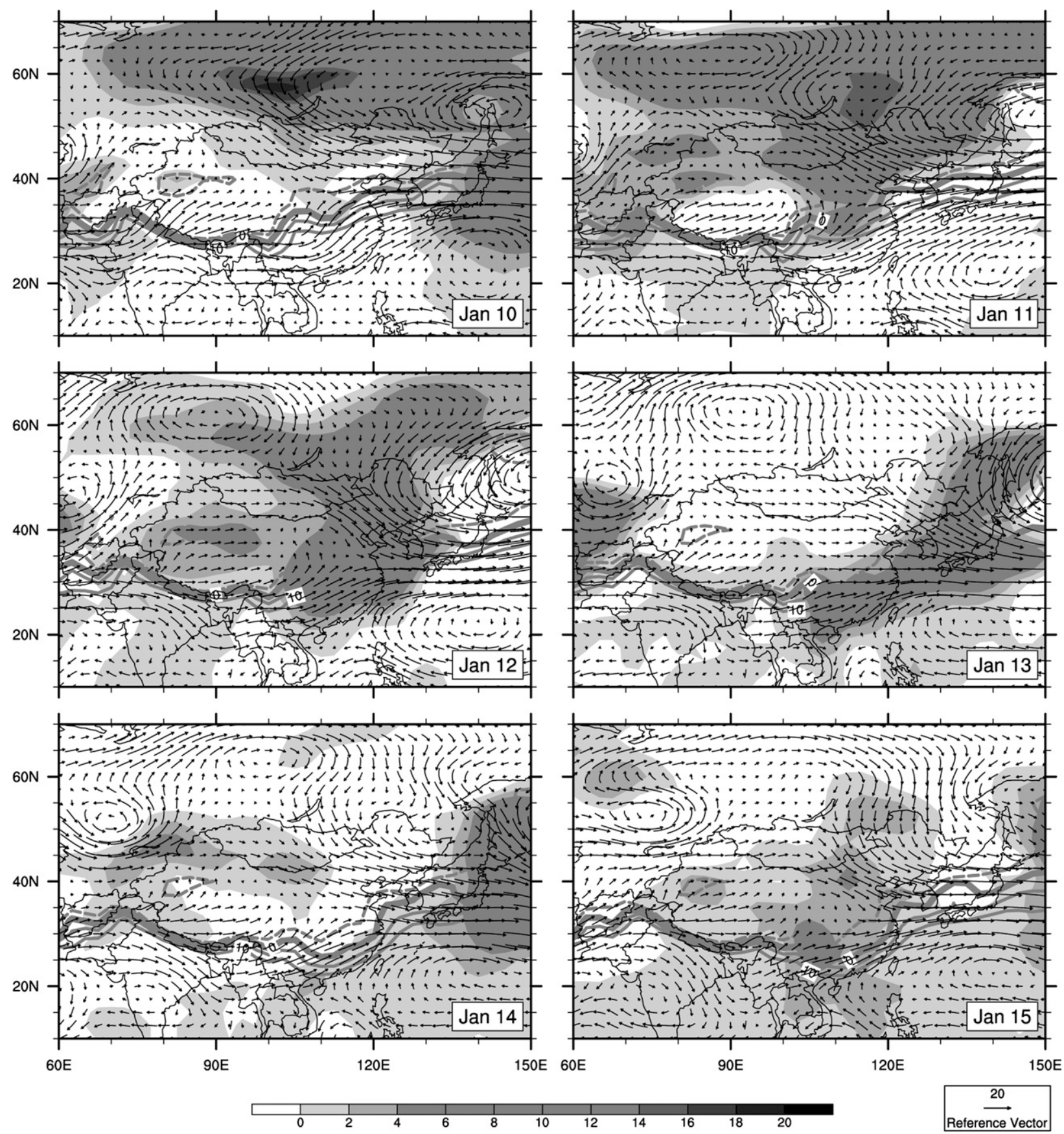

FIG. 5. The evolution process of the first snowstorm event (10-15 Jan 2008) that occurred in southern China: daily 850-hPa wind (vector, $\mathrm{m} \mathrm{s}^{-1}$ ), 24-h surface pressure difference (shaded, $\mathrm{hPa}$ ), and surface air temperature (contour interval $5^{\circ} \mathrm{C}$, red solid contour is $0^{\circ}$ isotherm).

\section{b. Persistent southwesterly flow over southern China}

As shown in Fig. 3, the 5800-gpm contour is farther north compared to climatology, a much stronger subtropical high prevailed over South China Sea, and the western North Pacific (5860-gpm contour) through the month of January 2008 (Fig. 3b). This strong western
Pacific subtropical high may have been related to the 2007/08 La Niña conditions . Li et al. (2001) found that La Niña event could enhance the East Asia winter monsoon via teleconnection. It seems that the prevalence of the La Niña condition in the central equatorial Pacific caused a stronger-than-normal subtropical high that forced the westerly flow from the Bay of Bengal 

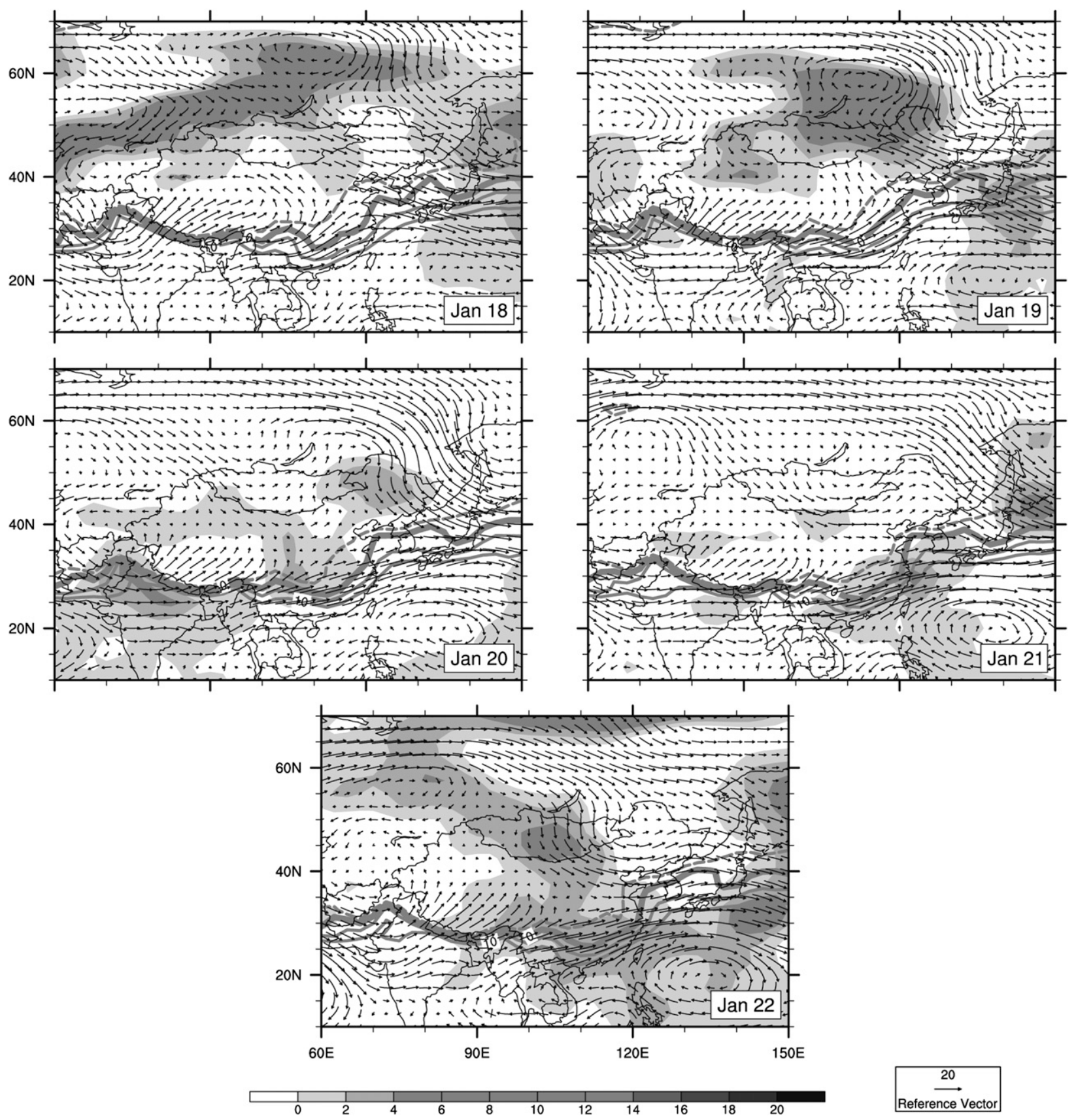

FIG. 6. As in Fig. 4, but for the second snowstorm event (18-22 Jan 2008).

(BOB) to move northeastward over southern China. Under such a pattern, a flow moves over the Indian Peninsula around the Tibetan Plateau (Figs. 5-8). Obviously, the $\mathrm{BOB}$ trough allows this flow to move over $\mathrm{BOB}$ and then toward the east. In normal years, this flow generally moves over the Indochina Peninsula, over the South China Sea (SCS), and into the western North Pacific Ocean. However, the flow in January 2008 that moved over the BOB was forced to take on a more northeastward direction over southern China, as illustrated in Figs. 5-8. This southwesterly flow then brought warm and moist air to southern China. This warm, moist air from the south (Indian Ocean and SCS) met the cold air from the north (Eurasia continent) to cause an intense temperature gradient, enhancing convection, hence raising the warm most air over the cold surface layer. At a higher altitude, the moisture condensed and formed clouds, which eventually led to precipitation in 

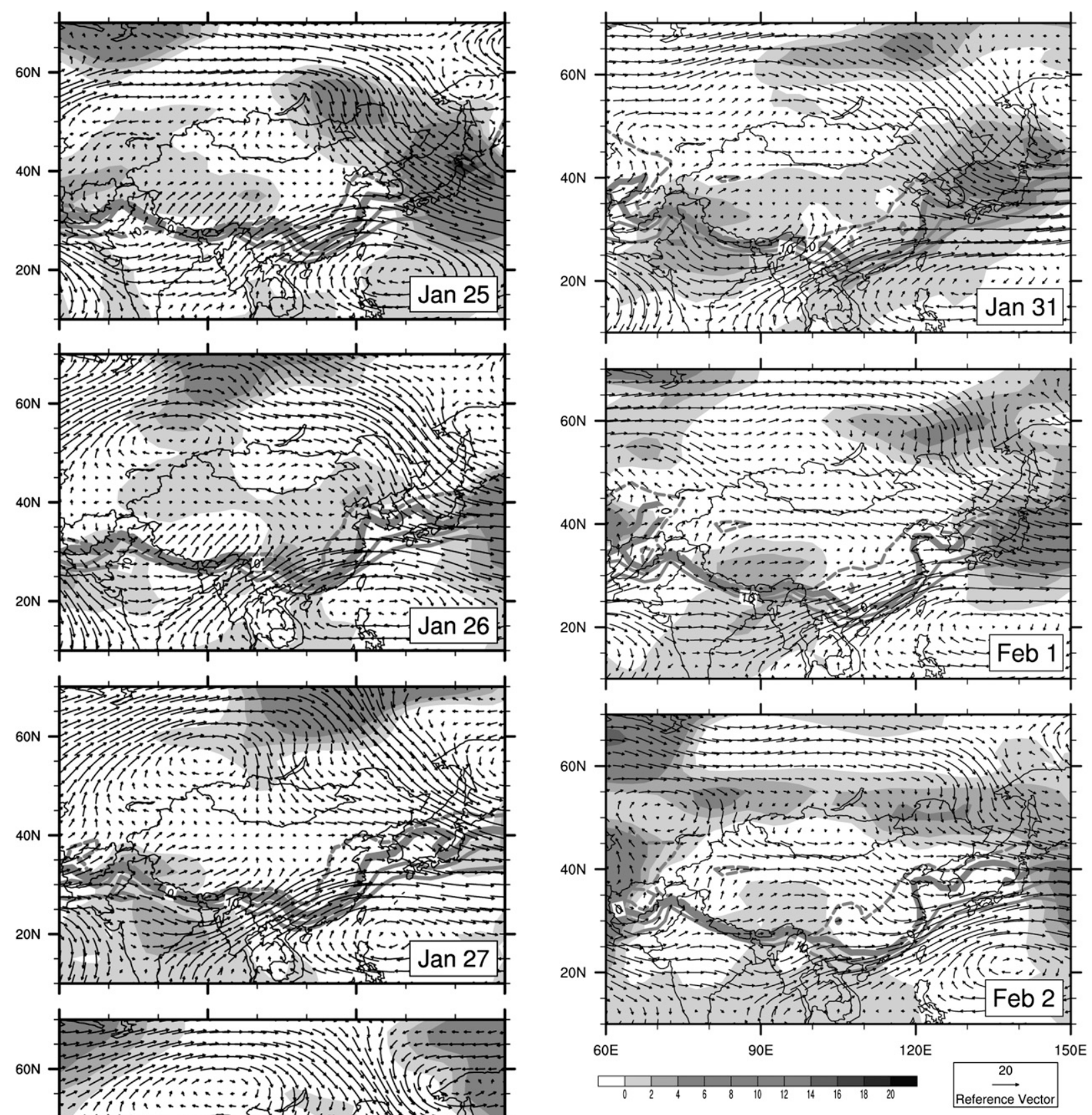

FIG. 8. As in Fig. 4, but for the fourth snowstorm event (31 Jan-2 Feb 2008).

the form of either rain or snow. Figure 9 shows the vertically integrated water vapor transport for the second and the third 10 days of January 2008 and their corresponding climate mean. Clearly, above-normal water vapor over southern China was transported from western Asia, the BOB, and the SCS. The transportation of water vapor during the second and the third 10 days in January 2008 was consistent with the circulation shown in Figs. 5-8. Note that the water vapor transport increased obviously after 15 January (Fig. 10). In other 

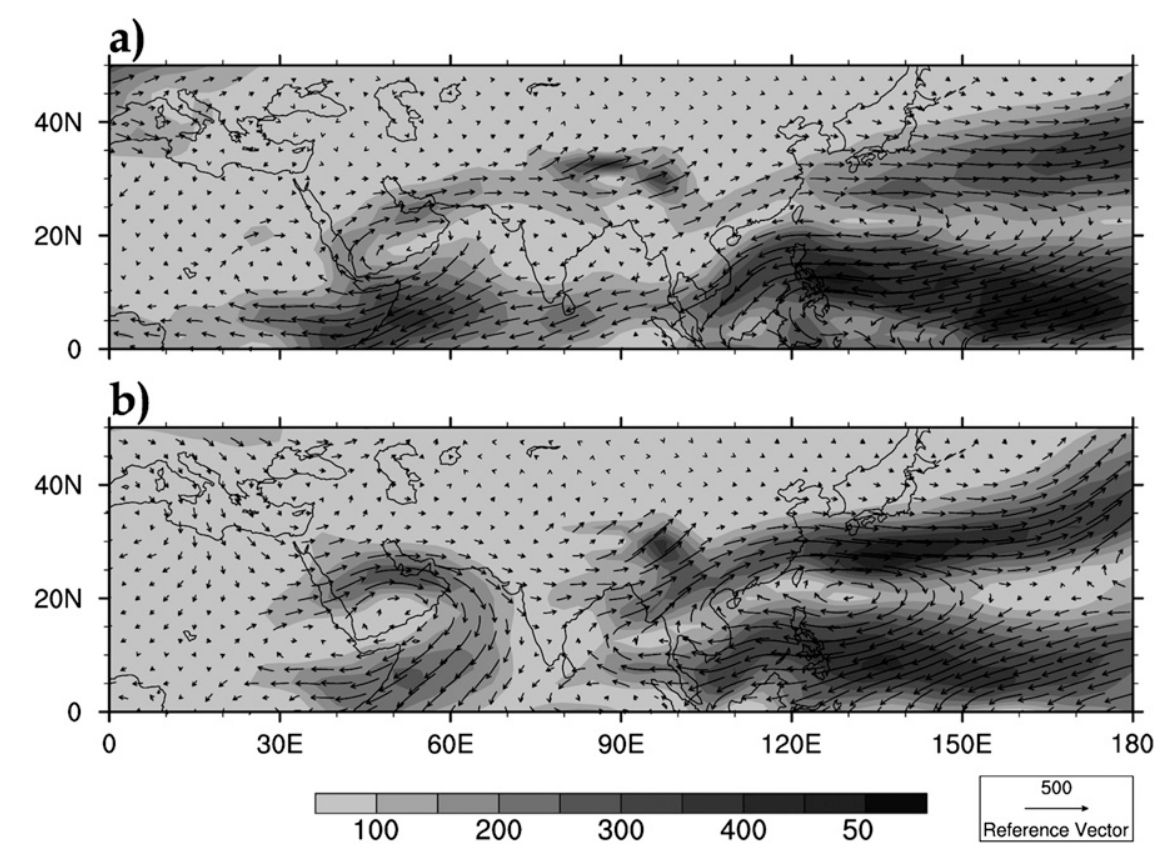

FIG. 9. Vertically averaged water vapor flux (surface to $300 \mathrm{hPa}$; vectors, $\mathrm{kg} \mathrm{m}^{-1} \mathrm{~s}^{-1}$ ) and the amount of water vapor transport (shading, $\mathrm{kg} \mathrm{m}^{-1} \mathrm{~s}^{-1}$ ) during (a) the second 10 days of January 2008 and (b) the third 10 days of January 2008.

words, the intensified southwesterly flow associated with the BOB trough and the western subtropical high provides an abnormally high water vapor transport from western Asia, the BOB, and the SCS-western Pacific. Thus, the convergence of water vapor over southern China may have enhanced the possibility of snowstorm over large areas when confronting with the cold air from the Siberian region.

\section{c. Deep inversion layer in the lower troposphere}

Our analysis suggests that the persistence of this blocking pattern supported the maintenance of cold temperatures over southern China after this first cold episode, and the ground remained snow-covered (data from the RCUL Web site indicate that the maximum snow extension was reached only at the end of January) and hence the air near the ground remained anomalously cold throughout this time period (Fig. 2). The role of the snow cover, moisture advection from the southwest, and high pressure influence aloft can be observed in the evolution of the radiosonde profiles over this area. As an example, Fig. 11 shows selected vertical profiles for the station Changsha (WMO number 57679, as a representative station of southern China, $28.13^{\circ} \mathrm{N}$, $\left.112.55^{\circ} \mathrm{E}\right)$. The first profile shows the situation before the first event (8 January, black lines), indicating some high pressure influence aloft but temperature and hu- midity conditions are close to average for this time of year., Starting on 11 January, the atmospheric soundings show (i) receding temperatures close to the surface (below $850 \mathrm{hPa}$ ), (ii) intrusion of moist air up to $650 \mathrm{hPa}$ (sometimes reaching $500 \mathrm{hPa}$ ), and (iii) subsidence and dryer air above the inversion layer. This development culminates with the conditions near the beginning of the third event, which is here documented with the vertical profile for 25 January (blue lines in Fig. 11). While the inversion in the lower troposphere is now very prominent (reaching $-7.5^{\circ} \mathrm{C}$ near $866 \mathrm{hPa}$ ), the air around $700-800 \mathrm{hPa}$ is much warmer (reaching $+6.6^{\circ} \mathrm{C}$ at $780 \mathrm{hPa}$ ) and humid. Above $675 \mathrm{hPa}$, the air is very dry. This will change in the next few days as the air mass above $600 \mathrm{hPa}$ becomes more humid (green lines in Fig. 11,

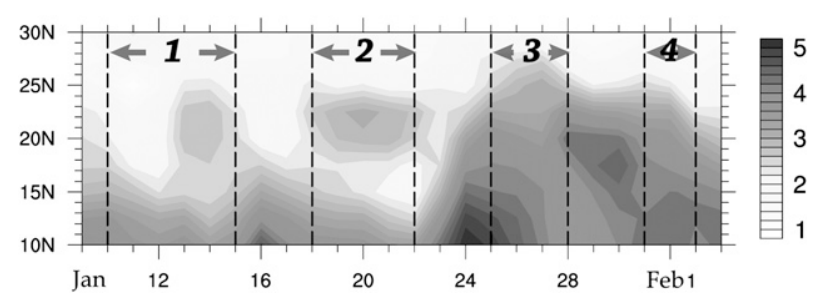

FIG. 10. Time-latitude cross section of the amount of water vapor transport along $105^{\circ} \mathrm{E}\left(\mathrm{kg} \mathrm{m}^{-1} \mathrm{~s}^{-1}\right)$ from $10 \mathrm{Jan}-2 \mathrm{Feb} 2008$. Numbers 1, 2, 3, and 4 refer to four snowstorm events $(10-15,18$ 22, 25-28 January, and 31 January-2 February) in 2008. 


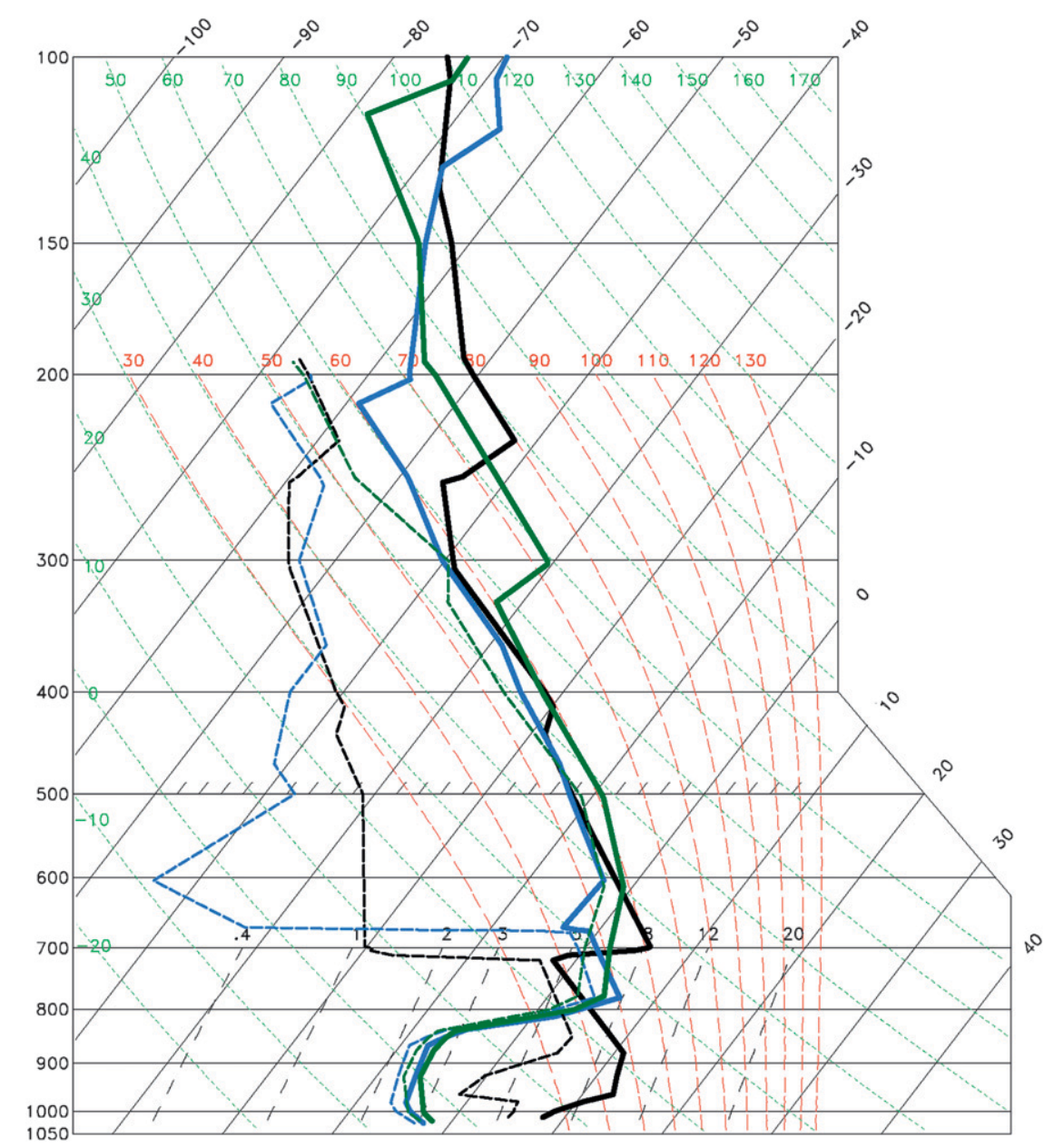

FIG. 11. Skew $T-\log p$ diagram of Changsha (WMO station number: 57679, the major sounding station for the box area in Fig. 1) at 0000 UTC 8 Jan 2008 (black lines), 25 Jan 2008 (blue lines), and 28 Jan 2008 (green lines). The solid (dashed) thick lines represent temperature (dewpoint) observations. Temperature in ${ }^{\circ} \mathrm{C}$ and pressure levels in $\mathrm{hPa}$.

0000 UTC 28 January) with the increasing intrusion of moist air from the BOB area (cf. Figs. 7 and 9b). Starting with the first cold episode of 10-15 January, the air was cold through a deep layer of the atmosphere so that the precipitation was generally in the form of snow and snowstorms occurred (Fig. 2). The associated precipitation mechanisms are mostly related with interactions between the cold and dry Siberia air mass and the warm and moist tropical air mass from $\mathrm{BOB}$ along the East Asian winter monsoon frontal zone (cf. Lau and Chang 1987; Ding 1994; Wu and Chan 1995, 1997; Chang 2004; Li et al. 2007).

The cold-air intrusions associated with the following three events (18-22 January, 25-28 January, and 31 January-2 February) are comparatively not as strong as the first event. As a result, when the warm air from the south was forced to rise, rain instead of snow formed. As the rain fell through the cold-air dome near the ground shown in Figs. 5-8, which had been persisting for some time, the rain froze and became freezing rain. Upon hitting cold objects such as tree branches, power lines, and the ground, ice formed. Starting early February, both the snow cover and surface inversion slowly receded as temperatures rose and the high pressure influence diminished.

\section{Discussion and conclusions}

This paper described an extraordinary, very rare and protracted cold event that occurred in southern China in January-February 2008. Beginning 10 January 2008, rare and extreme weather of low temperatures, rain, snow, and ice swept through southern China. The estimates for temperatures return periods for cities such as 

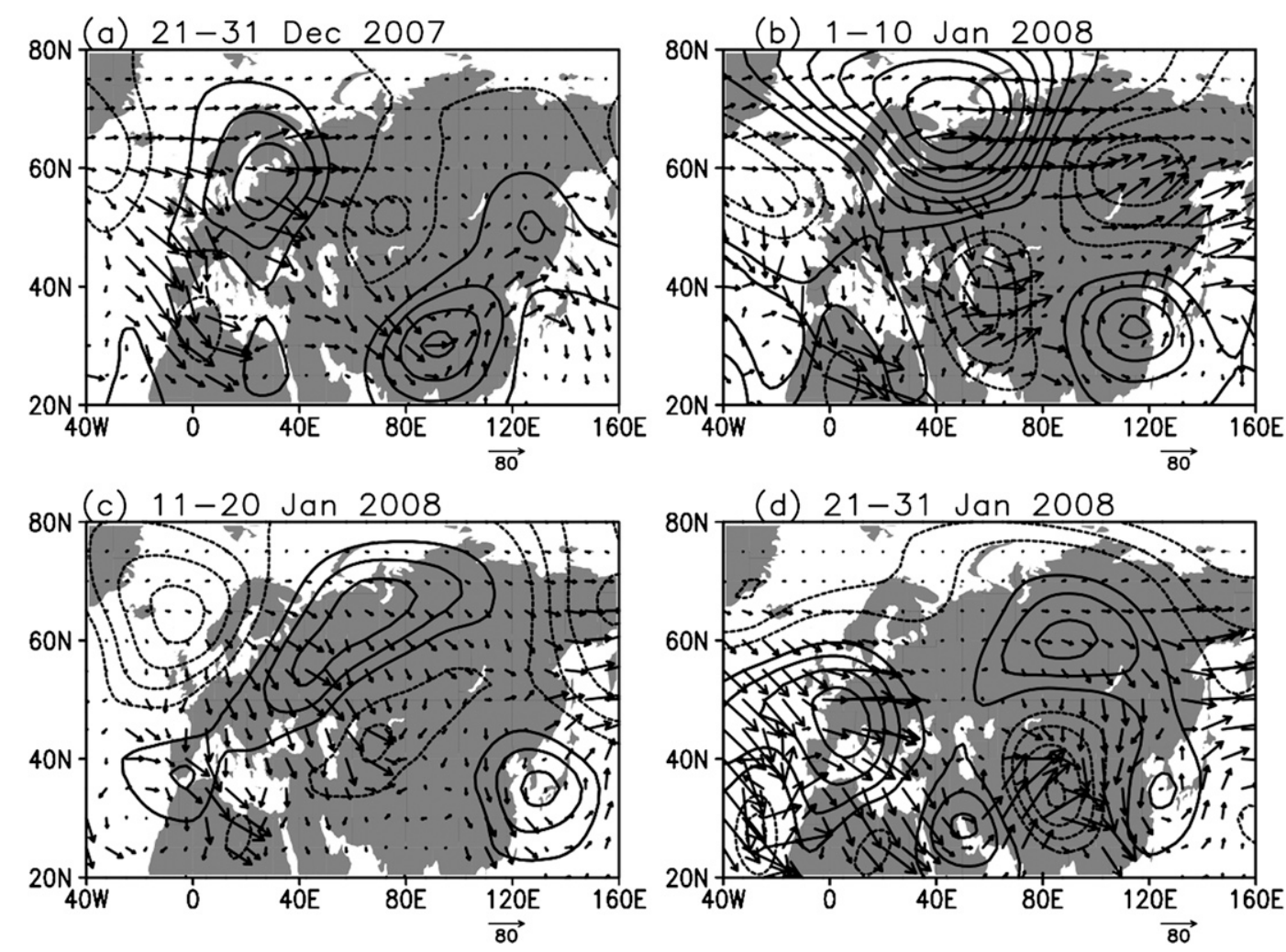

FIG. 12. Geopotential height anomalies from climatic mean (contour with interval of $50 \mathrm{gpm}$ ) and wave activities (vector, $\mathrm{m}^{2} \mathrm{~s}^{-2}$ ) at $200 \mathrm{hPa}$ during (a) 21-31 Dec 2007, (b) 1-10 Jan 2008, (c) 11-20 Jan 2008, and (d) 21-31 Jan 2008. Zero contour is omitted.

Yueyang, Hengyang, and Chenzhou are of 40-50 yr. Three meteorological factors could be responsible for this extreme winter event. First, a persistent blocking pattern existed in the midlatitudes. This not only allowed cold air to persist in southern China, but also enabled each perturbation from the west propagating around the blocking high to trigger downstream cold-air intrusions from the north. The persistent cold air also caused freezing of the rain. Second, a strong trough existed in the $\mathrm{BOB}$, this will provide the persistent southwesterly flow over southern China, and this flow brought warm and moist air to the region, which then caused condensation and subsequent rain or snow. Third, there was a deep inversion layer in the lower troposphere above southern China, which was associated with the extended snow cover over China. The juxtaposition of these flow patterns thus allowed the occurrence of persistent cold and rainy, snowy, and icy conditions over southern China. As we mentioned in section 3, the southwesterly wind associated with the BOB trough and western Pacific subtropical high could provide plenty moisture from Indian Ocean and South China Sea to southern China. When the cold air from the north met the warm air from the south at southern
China, the water moisture condensed and became snow or freezing rain.

Among these three factors, the blocking pattern is likely to be the most important because it was responsible for establishing and maintaining the cold conditions over southern China. The link between high pressure centers over Russia/Siberia and cold-air outbreaks over southeastern Asia has been documented in many previous studies (e.g., Ding and Krishnamurti 1987; Lau and Chang 1987; Ding 1994; Wu and Chan 1995, 1997; Chang 2004). The persistence of the blocking was extraordinary in climatological terms (section 3), particularly for the longitudes $57.5^{\circ}-67.5^{\circ} \mathrm{E}$, for which the highest blocking frequencies on record were found. Therefore, the snowfall in China is closely related to this strongest blocking for $57.5^{\circ}-67.5^{\circ} \mathrm{E}$. Figure 12 shows that this blocking might be due to strong nonlinear interaction among waves and mean flow. At the end of December (Fig. 12a) and the beginning of January (Fig. 12b), the quasi-stationary wave train is found from the Atlantic to European continent, which might amplify the blocking around Ural region. The result here is also consistent with previous findings by Nakamura et al. (1997). Wintertime blocking over the Ural Mountains is of great 
a)

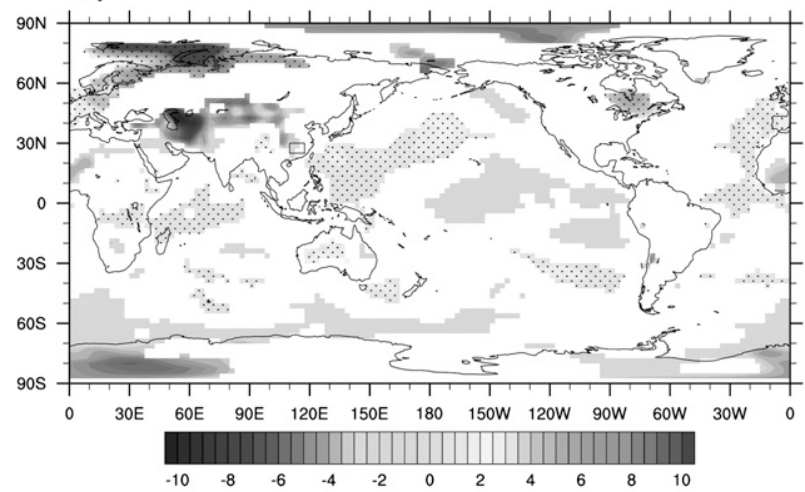

b)

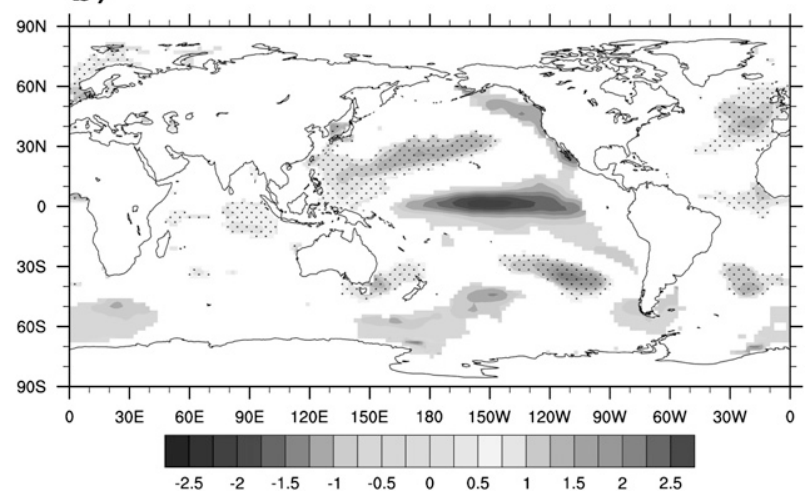

FIG. 13. (a) Land and SSTAs in January 2008 and (b) SSTAs in January 2008. The shading areas indicate the absolute temperature anomalies larger than one standard deviation of the climatology mean of $1978-2007$, values in ${ }^{\circ} \mathrm{C}$. The box in (a) indicates the location of the most affected area (cf. Fig. 1).

importance for the climate of downstream regions such as East Asia, as blocking events in this region are usually followed by the amplification of the Siberian high (Takaya and Nakamura 2005) and subsequent outbreaks of cold air in East Asia (Joung and Hitchman 1982; Ding and Krishnamurti 1987). The wave activity propagation of shown in Fig. 12b would be related to the development of Ural blocking. Clearly there are quasistationary waves propagating eastward from the Ural Mountain region to Siberia after the establishment of the blocking (Figs. 12c,d). These waves meet a strong western Pacific high, which may be related to La Niña, and turn to the south. Hence, these wave propagations bring cold air to the southern part of China.

In future work, the driving mechanisms responsible for this persistent blocking should be examined. A preliminary analysis suggests the following factors. First, the snow cover over Eurasia in January 2008 was the highest on the RCUL record (since 1966), possibly leading to a positive feedback, hence supporting the high pressure system (Garcia-Herrera and Barriopedro 2006). Second, (remote) midlatitude teleconnections may have supported the occurrence and/or persistence of the blocking at this location: the Arctic Oscillation (e.g., Thompson and Wallace, 1998) has been previously linked both to the intensity/location of the Siberian high and to the East Asian winter monsoon (cf. e.g., Wu and Wang 2002; Jeong and Ho 2005). On more regional terms, Barriopedro et al. (2006) suggested that a positive Scandinavian pattern (e.g., Barnston and Livezey 1987) index is significantly associated with blocking events between $10^{\circ} \mathrm{W}$ and $75^{\circ} \mathrm{E}$. The Scandinavian pattern was indeed in its positive phase (typically associated with below-average temperatures across central Russia) in January 2008, and hence it may have supported the occurrence and persistence of the blocking. Moreover, land-ocean temperature contrast between the North Atlantic (SST was above average, Fig. 13) and cold Eurasia may have supported the development and maintenance of the blocking. Further reasons for the long enduring event may be associated with to the landsea thermal contrast over Asia. In January 2008, the sea surface temperature anomalies observed over the $\mathrm{Pa}$ cific shows the La Niña condition with warming over the tropical western Pacific and cooling over the tropical eastern Pacific (Fig. 13).

TABLE A1. The recurrence extreme averaged temperature $\left({ }^{\circ} \mathrm{C}\right)$ of the second 10 days in January 2008 at 9 observation stations in southern China.

\begin{tabular}{cccrrrrrrrr}
\hline \hline Station & $10 \mathrm{yr}$ & $20 \mathrm{yr}$ & $30 \mathrm{yr}$ & $40 \mathrm{yr}$ & $50 \mathrm{yr}$ & $60 \mathrm{yr}$ & $70 \mathrm{yr}$ & $80 \mathrm{yr}$ & $90 \mathrm{yr}$ & $100 \mathrm{yr}$ \\
\hline 1 & 1.74 & 0.68 & 0.05 & -0.40 & -0.75 & -1.03 & -1.28 & -1.49 & -1.67 & -1.84 \\
2 & 1.40 & 0.26 & -0.42 & -0.91 & -1.29 & -1.60 & -1.86 & -2.08 & -2.28 & -2.46 \\
3 & 2.07 & 1.01 & 0.38 & -0.08 & -0.43 & -0.71 & -0.96 & -1.17 & -1.36 & -1.52 \\
4 & 2.73 & 1.59 & 0.91 & 0.43 & 0.05 & -0.26 & -0.52 & -0.75 & -0.94 & -1.12 \\
5 & 2.31 & 1.07 & 0.33 & -0.19 & -0.60 & -0.94 & -1.22 & -1.47 & -1.69 & -1.88 \\
6 & 3.11 & 1.98 & 1.32 & 0.88 & 0.47 & 0.16 & -0.09 & -0.32 & -0.51 & -0.69 \\
7 & 3.11 & 1.98 & 1.32 & 0.84 & 0.47 & 0.16 & -0.09 & -0.32 & -0.51 & -0.69 \\
8 & 2.22 & 0.86 & 0.06 & -0.51 & -0.96 & -1.33 & -1.64 & -1.90 & -2.14 & -2.35 \\
9 & 4.43 & 3.16 & 2.40 & 1.86 & 1.43 & 1.09 & 0.80 & 0.54 & 0.32 & 0.12 \\
\hline
\end{tabular}


TABLE A2. As in Table A1, but for the third 10 days in January 2008.

\begin{tabular}{ccrrrrrrrrr}
\hline \hline Station & $10 \mathrm{yr}$ & $20 \mathrm{yr}$ & $30 \mathrm{yr}$ & $40 \mathrm{yr}$ & $50 \mathrm{yr}$ & $60 \mathrm{yr}$ & $70 \mathrm{yr}$ & $80 \mathrm{yr}$ & $90 \mathrm{yr}$ & $100 \mathrm{yr}$ \\
\hline 1 & 1.23 & -0.01 & -0.75 & -1.28 & -1.69 & -2.02 & -2.31 & -2.55 & -2.77 & -2.97 \\
2 & 1.08 & -0.26 & -1.05 & -1.62 & -2.07 & -2.43 & -2.73 & -3.00 & -3.23 & -3.44 \\
3 & 1.85 & 0.58 & -0.17 & -0.71 & -1.13 & -1.47 & -1.76 & -2.01 & -2.23 & -2.43 \\
4 & 2.97 & 1.72 & 0.98 & 0.45 & 0.03 & -0.30 & -0.59 & -0.84 & -1.06 & -1.25 \\
5 & 2.04 & 0.66 & -0.15 & -0.74 & -1.19 & -1.56 & -1.87 & -2.15 & -2.39 & -2.60 \\
6 & 2.79 & 1.43 & 0.62 & 0.04 & -0.41 & -0.78 & -1.09 & -1.36 & -1.60 & -1.81 \\
7 & 2.97 & 1.58 & 0.75 & 0.16 & -0.30 & -0.68 & -1.00 & -1.27 & -1.52 & -1.74 \\
8 & 2.23 & 0.76 & -0.12 & -0.75 & -1.24 & -1.63 & -1.97 & -2.27 & -2.52 & -2.75 \\
9 & 4.16 & 2.66 & 1.76 & 1.13 & 0.63 & 0.23 & -0.11 & -0.41 & -0.67 & -0.91 \\
\hline
\end{tabular}

A detailed analysis of these possible driving mechanisms, particularly in terms of their relative importance to the development of the events, is beyond the scope of the present study. This will be the topic of a subsequent study, which will also consider past occurrences of similar blocking patterns and other intense winter monsoon events. An analysis of the cause leading to these events should provide, in the long term, a better predictability of such developments, which in turn could bring socioeconomic benefits by forewarning of winter climate anomalies and their impacts on business revenue, commerce, and society.

Acknowledgments. This work was supported by the 973 Basic Research Program Grant 2009CB421400, Joint National Natural Science Foundation of China Project U0733002, and the City University of Hong Kong Strategic Research Grants 7002231 and 7002329. Wen Zhou was supported by a Humboldt Research Fellowship during her visit in 2008 at the Institute for Geophysics and Meteorology of the University of Cologne, Germany. We are thankful to Mark Reyers, Volker Ermert, and Dr. Lin Wang for help with Figs. 4, 11 , and 12 .

\section{APPENDIX}

\section{Recurrence Tables for Observational Stations over Southern China}

These tables include the recurrence extreme values for 10-day-averaged temperatures for the nine stations considered in Tables A1 and A2.

\section{REFERENCES}

Barnston, A. G., and R. E. Livezey, 1987: Classification, seasonality, and persistence of low-frequency atmospheric circulation patterns. Mon. Wea. Rev., 115, 1083-1126.
Barriopedro, D., R. García-Herrera, A. R. Lupo, and E. Hernández, 2006: A climatology of Northern Hemisphere blocking. J. Climate, 19, 1042-1063.

Chang, C.-P., E.d., 2004: East Asian Monsoon. Vol. 2, World Scientific Series on Meteorology of East Asia, World Scientific, 600 pp.

Chen, H., and Z. Huang, 1995: Application of Gumbel mixture extreme theory and maximum likelihood to estimate the seismic risk of the Chinese mainland. ACTA Seismol. Sin., 8, 325-331.

Ding, Y., 1994: Monsoons over China. Kluwer Academic Publishers, $419 \mathrm{pp}$.

— , and T. N. Krishnamurti, 1987: Heat budget of the Siberian high and the winter monsoon. Mon. Wea. Rev., 115, 2428-2449.

Garcia-Herrera, R., and D. Barriopedro, 2006: Northern hemisphere snow cover and atmospheric blocking variability. J. Geophys. Res., 111, D21104, doi:10.1029/2005JD006975.

Gumbel, E. J., 1960: Multivariate extremal distributions. Bull. Inst. Int. Stat., 37, 471-475.

_ 1961: Bivariate logistic distributions. J. Amer. Stat. Assoc., 56, 335-349.

Jeong, J.-H., and C.-H. Ho, 2005: Changes in occurrence of cold surges over East Asia in association with Arctic Oscillation. Geophys. Res. Lett., 32, L14704, doi:10.1029/ 2005 GL023024.

Joung, C. H., and M. H. Hitchman, 1982: On the role of successive downstream development in East Asian polar air outbreaks. Mon. Wea. Rev., 110, 1224-1237.

Kalnay, E., and Coauthors, 1996: The NCEP/NCAR 40-Year Reanalysis Project. Bull. Amer. Meteor. Soc., 77, 437-471.

Lau, K. M., and C. P. Chang, 1987: Planetary scale aspects of the winter monsoon and atmospheric teleconnections. Review of Monsoon Meteorology, C. P. Chang and T. N. Krishnamurti, Eds., Oxford University Press, 161-202.

Li, C., S. Q. Sun, and M. Q. Mu, 2001: Origin of the TBO-interaction between anomalous East Asian Winter monsoon and ENSO cycle. Adv. Atmos. Sci., 18, 554-566.

Li, Q. P., Y. H. Ding, W. J. Dong, and G. Yan, 2007: A numerical study on the winter monsoon and cold surge over East Asia. Adv. Atmos. Sci., 24, 664-678.

Nakamura, H., M. Nakamura, and J. L. Anderson, 1997: The role of high- and low-frequency dynamics in blocking formation. Mon. Wea. Rev., 125, 2074-2093.

Robinson, D. A., K. F. Dewey, and R. R. Heim, 1993: Global snow cover monitoring, An update. Bull. Amer. Meteor. Soc., 74, 1689-1696. 
Takaya, K., and H. Nakamura, 2005: Mechanisms of intraseasonal amplification of the cold Siberian high. J. Atmos. Sci., 62, 4423-4440.

Thompson, D. W. J., and J. M. Wallace, 1998: The arctic oscillation signature in the wintertime geopotential height and temperature fields. Geophys. Res. Lett., 25, 1297-1300.

Tibaldi, S., and F. Molteni, 1990: On the operational predictability of blocking. Tellus, 42A, 343-365.
Wu, B., and J. Wang, 2002: Possible impact of winter Arctic Oscillation on Siberian High, the East Asian winter monsoon and sea-ice extent. Adv. Atmos. Sci., 19, 297-320.

Wu, M. C., and J. C. L. Chan, 1995: Surface features of winter monsoon surges over South China. Mon. Wea. Rev., 123, 662-680. , and — 1997: Upper-level features associated with winter monsoon surges over South China. Mon. Wea. Rev., 125, 317-340. 